\title{
Charge Carrier Mobility in Phthalocyanines: Experiment and Quantum Chemical Calculations
}

\author{
Irena Kratochvilova \\ Institute of Physics, Academy of Sciences of the Czech Republic, Prague, \\ Czech Republic
}

\section{Introduction}

The main goal of this chapter is to show how and why quantum chemistry modeling can /should be applied on class of organic materials with relatively high carrier mobility phthalocyanines $\left(\mathrm{H}_{2} \mathrm{Pc}, \mathrm{NiPc}\right.$ and $\left.\mathrm{NiPc}\left(\mathrm{SO}_{3} \mathrm{Na}\right)_{x}\right)$. It will be shown how Density Functional Theory (DFT) can be used to calculate/model main parameters that influence the group of material properties that are crucial from practical point of view.

With the ongoing miniaturization of microelectronics, functional elements in electronic circuits may soon consist of only a couple of electrons or molecules. We therefore address the question how the physical laws which hold for macroscopic solids become modified when one deals with very small structures. It turns out that down-scaling of electronic properties from the macro world to the atomic or molecular level does not work at all. For example, the famous Ohm's law does not hold anymore, because the resistance does not scale with the length of a "quantum wire" [1-15].

Once having realized this fundamental issue, one immediately conceives this as a chance to develop new concepts. Instead of continuously scaling down, as in industrial chip designs, one considers building up electronic circuits with tailored properties "bottom up". The first questions which have to be answered now are: "Which atoms or molecules have to be combined in which way to achieve the desired properties?" and: "Which physical and chemical properties determine the electrical conductance of atomic-size or molecular-size circuits?".

In most areas of science, there are free major steps that need to be taken for understanding to be gleaned: the first is synthesis and preparation, the second is measurements and characterization and third is theory and modelling [12-20]. The great advance in measurement and characterization was clearly the advent of scanning probe microscopy which permitted measurements both of structure and of transport at the level of one to a few molecules. The critical advances in theory and modelling came with adaption of the coherent tunnelling models originally developed by Landauer to the study of transport in molecular tunnel junctions [20-31].

Current research focuses, among others, on the design and implementation of nanometer scale electronic systems which exhibit new classical and quantum mechanical effects. The 
motivation for creating such elements has been two-fold: first, to create nanoscale laboratories to explore physics in a new way, and second, to develop novel devices with significant applications. The architecture of molecular-scale electronic devices can be designed starting from molecular segments whose properties have been known from experiment and/or suitable theoretical models. The field of "Molecular Electronics" has been opened by the seminal proposition of A. Aviram and M. Ratner in 1974 to build a diode from a single molecule [1-2]. Since then, it took almost 20 years before the first molecular diode was experimentally realized. By now, molecular electronics is a broad field of research world-wide [3-21].

Some examples of molecular nanostructures that might be used as switching units, memories, logic elements and devices embodying a negative resistance have recently been demonstrated (e.g., [1-5]). A pioneering construction of a molecular switch was based on the electron tunneling principle [1]. An electron travels along a 'molecular wire' (e.g., a conjugated polymer chain) containing a finite series of periodic potential walls. The tunnel switch is 'on' if the transmission coefficient of the electron is close to unity, i.e., if the electron energy matches pseudostationary energy levels of the walls, and can be turned off by either changing a barrier height or the depth of a potential well, which can be controlled by the dipole moment of polymer side groups.

As we have already mentioned the charge transport in molecular electronic materials is a very complex process which can be affected by many physical and chemical parameters; the knowledge of its nature is crucial for the development and optimization of molecular-based devices. Each step forward in understanding and controlling the charge transport is extremely important for the practical applications of molecular systems in electronics [1-16].

One of the reasons for the difficulties in charge-transport phenomena/conditions description is the lack of a well-understood mechanism of charge transport in organic materials. The charge-carrier transport in molecular systems is a very complicated and comprehensive event affected by many parameters. In the early days, band theory was applied to predict the charge-carrier mobility in organic materials. However, it was repeatedly pointed out by several authors [18-21] that this approach is not suitable. Comparing organic and inorganic semiconductors, the materials from the latter class are usually less disordered and have molecular sites closer to one another. For disordered materials, the hopping mechanism seems to be more appropriate for the description of the charge-carrier behaviour. In this approach, the charge carrier is localised on the molecular site and jumps to the other site by overcoming some energy barrier. However, for materials possessing a preferred direction of charge-carrier transport like phtalocyanines we need a combination of different approaches for the description of the charge-carrier motion along the preferred paths and for hopping among them.

Molecular materials are generally not very good conductors. Main limitation follows from low charge carrier "on-chain" mobility which mostly using the microwave photoconductivity was found to be $10^{-5} \mathrm{~m}^{2} \mathrm{~V}^{-1} \mathrm{~s}^{-1}$ and $10^{-4} \mathrm{~m}^{2} \mathrm{~V}^{-1} \mathrm{~s}^{-1}$, for $\sigma$ - and $\pi$-conjugated molecular materials, respectively. The mobility is limited by polaron formation and by the dispersion of transfer integrals among the monomer units the wire. Electrical current through a single molecule is influenced by charge tunnelling - the Fowler-Nordheim model seems to be a good approximation for the description of charge transport. The presence of 
dipolar species results in the mobility decrease due to the increase of the transfer integral dispersion. Polar group chemically attached to the molecular wire, can cause the orbital localization. The charge transport in 3D samples can be described by the theory of disordered polarons which postulates that the activation energy of the charge carrier mobility is composed of contribution both from the dynamic disorder, i.e. the polaronic barrier, and from the static disorder, i.e. the variation of the energy of transport states as a result of the environment. The main contribution to the polaron binding energy results from molecular deformation; electron-phonon term makes for $20 \%$ only. Dipolar additives make the distribution of hopping states broadened and new localized states for charge carriers are formed; it results in the reduction of charge mobility [17-19].

Experimentally measured conductivity is a macroscopic phenomenon and reflects on-stack mobility plus intra-stack hopping mobility. Intra-stack transport mainly contributes to the whole resistivity - i.e. the main charge-transport obstruction is between stacks.

From the charge carrier mobility point of view phtalocyanines seem to be promising materials - in devices with vacuum evaporated phthalocyanine thin films, the values reached from $10^{-5}$ to $10^{-4} \mathrm{~cm}^{2} \mathrm{~V}^{-1} \mathrm{~s}^{-1}$, when phthalocyanine was evaporated on hot substrates the value increased up to $10^{-2} \mathrm{~cm}^{2} \mathrm{~V}^{-1} \mathrm{~s}^{-1}$ [15-22]. Preliminary results obtained on sulphonated phthalocyanines, i.e., materials containing both electronic and electrolytic segments, seem to be very promising. The charge carrier mobility determined from the dependences of the source-drain current vs. the source-drain voltage of the OFET was surprisingly high. In the case of $\mathrm{NiPc}\left(\mathrm{SO}_{3} \mathrm{Na}\right)_{4}$, the field-effect mobility was $0.02 \mathrm{~cm}^{2}$ $\mathrm{V}^{-1} \mathrm{~s}^{-1}[12]$.

Phthalocyanines can be organized in columns at a supramolecular level, giving rise to conducting properties. The cofacial stacking of metallophthalocyanines enables electron delocalization along the main axis of the column through $\Pi-\Pi$ orbital overlapping. Metallophthalocyanines generally crystallize in an inclined stacked insulating arrangements called a or $\beta$-modifications that do not allow an appropriate overlap of $\Pi$-orbitals and hence no formation of a conduction band. Only in few cases stacked arrangements are found, being the most representative the nonplanar cone-shaped phthalocyaninatolead (II) ( $\mathrm{PbPc}$ ) in its monoclinic modification.

In the last few years, phthalocyanines (Fig. 1) are being intensively studied as targets for optical switching and limiting devices, organic field effect transistors, sensors, light-emitting devices, low band gap molecular solar cells, optical information recording media, photosensitizers for photodynamic therapy, and nonlinear optical materials, among others. Phthalocyanines will burst also in a very near future into the nanotechnology field.

Phthalocyanine is an intensely blue-green coloured macrocyclic compound. Phthalocyanines form coordination complexes with most elements of the periodic table. Phthalocyanines are structurally related to other macrocyclic pigments, especially the porphyrins. Four pyrrolelike subunits are linked to form a 16-membered ring. The pyrrole-like rings within $\mathrm{H}_{2} \mathrm{Pc}$ are closely related to isoindole. Both porphyrins and phthalocyanines function as planar tetradentate dianionic ligands that bind metals through four inwardly projecting nitrogen centers. Such complexes are formally derivatives of $\mathrm{Pc}^{2-}$, the conjugate base of $\mathrm{H}_{2} \mathrm{Pc}$. 


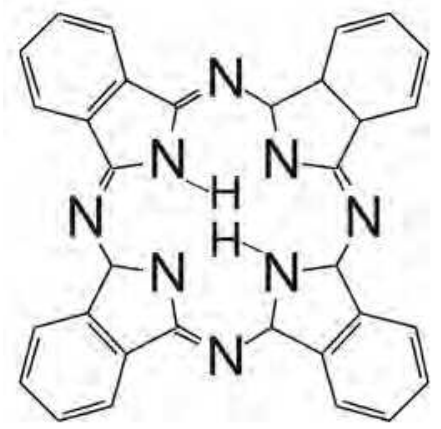

Fig. 1. Chemical structure of $\mathrm{H}_{2}$ phthalocyanine $\left(\mathrm{H}_{2} \mathrm{Pc}\right)$.

Many derivatives of the parent phthalocyanine are known, where either carbon atoms of the macrocycle are exchanged for nitrogen atoms or where the hydrogen atoms of the ring are substituted by functional groups like halogens, hydroxy, amino, alkyl, aryl, thiol, alkoxy, nitro, etc.

Due to phthalocyanine stack formation and the presence of ionic groups charge transport consists of an electronic feature through the stack, charge hopping among the stacks and ionic type of the transport.

In order to model the physical properties of $\mathrm{H}_{2} \mathrm{Pc}$ layer, quantum chemical calculations on $\mathrm{H}_{2} \mathrm{Pc}$ dimers and tetramers were performed at DFT level. The $\alpha$ and $\beta$ types of polymorph of $\mathrm{H}_{2} \mathrm{Pc}$ dimer structures were optimized using several density functionals. The optimizations lead to geometry with almost parallel orientation of $\mathrm{H}_{2} \mathrm{Pc}$ planes. The optimised conformer structures are depicted in Fig. 2, the structural parameters calculated for different functional and basis sets are listed in Table 1.

a)
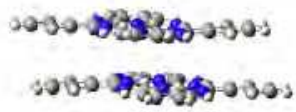

b)

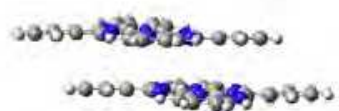

c)

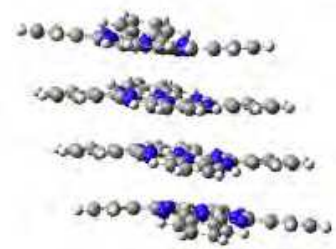

Fig. 2. DFT calculated optimized structures of $\mathrm{H}_{2} \mathrm{Pc}$ dimers and tetramer. In the figure, a) $\alpha-$ modification of $\mathrm{H}_{2} \mathrm{Pc}$ dimer b) $\beta$-modification of $\mathrm{H}_{2} \mathrm{Pc}$ dimer c) $\alpha$-modification of $\mathrm{H}_{2} \mathrm{Pc}$ tetramer, respectively.

Calculated geometry of $\mathrm{H}_{2} \mathrm{Pc}$ dimer reasonably well represents the local part of the experimental structure of phthalocyanine films [15-19]. The best performance was found for MPW1B95/6-31+G* calculations, where calculated structures fit the phthalocyanine stacking in the crystal. For $\alpha$-modification, the calculated structural parameter $b=3.77 \AA$, derived as averaged distances of corresponding atoms at individual monomers well reproduces the experimental value of $3.81 \AA$. The calculated approximate interplane distance $(3.48 \AA)$ is close to experimental value of $3.4 \AA$ [15] as well. For $\beta$-modification, the calculations give the 
interplane distance $3.46 \AA$ (experiment $3.4 \AA$ ) and parameter $\mathrm{b}=4.87 \AA$ (experiment 4.72 ). The inclusion of diffusion functions $\left(6-31+G^{*}\right.$ basis) does not substantially change the structural parameters. As shown in Table 1, for $\alpha$-modification the functional MPW1B95 slightly better describes the distance parameter $b$ than MPWB1K. For $\beta$-modification, the performance of both functional is comparable. Standard B3LYP functional strongly overestimates the separation of molecular planes and fails to predict the real structure.

\begin{tabular}{|c|c|c|c|c|c|}
\hline DFT Functional & \multicolumn{2}{|c|}{ MPW1B95 } & \multicolumn{2}{|c|}{ MPWB1K } & Experiment \\
\hline \multirow[t]{2}{*}{ Basis Set } & $6-31 G^{*}$ & $6-31+G^{*}$ & $6-31 G^{*}$ & $6-31+G^{*}$ & \\
\hline & \multicolumn{2}{|c|}{$(\AA)$} & \multicolumn{2}{|c|}{$(\AA)$} & $(\AA)$ \\
\hline \multicolumn{6}{|c|}{$\mathrm{H}_{2} \mathrm{Pc}$ dimer polymorph a } \\
\hline \multicolumn{6}{|l|}{ neutral } \\
\hline$a^{1}$ & 3.463 & 3.478 & 3.442 & 3.466 & 3.4 \\
\hline$b^{2}$ & 3.744 & 3.768 & 3.721 & 3.752 & 3.81 \\
\hline$\Delta \mathrm{E}^{3}$ & 5.1 & 4.6 & & & \\
\hline \multicolumn{6}{|l|}{ cation } \\
\hline$a^{1}$ & 3.440 & & & & \\
\hline$b^{2}$ & 3.665 & & & & \\
\hline \multicolumn{6}{|l|}{ anion } \\
\hline $\mathrm{a}^{1}$ & 3.450 & & & & \\
\hline$b^{2}$ & 3.804 & & & & \\
\hline
\end{tabular}

\begin{tabular}{|c|c|c|c|c|c|}
\hline \multicolumn{6}{|c|}{$\mathrm{H}_{2} \mathrm{Pc}$ dimer polymorph $\beta$} \\
\hline \multicolumn{6}{|l|}{ neutral form } \\
\hline$a^{1}$ & 3.428 & 3.456 & 3.428 & 3.432 & 3.4 \\
\hline$b^{2}$ & 4.849 & 4.871 & 4.840 & 4.841 & 4.72 \\
\hline$\Delta \mathrm{E}^{3}$ & 3.6 & 3.0 & & & \\
\hline \multicolumn{6}{|l|}{ cation } \\
\hline$a^{1}$ & 3.289 & & & & \\
\hline$b^{2}$ & 5.255 & & & & \\
\hline \multicolumn{6}{|l|}{ anion } \\
\hline$a^{1}$ & 3.325 & & & & \\
\hline$b^{2}$ & 4.678 & & & & \\
\hline \multicolumn{6}{|c|}{$\mathrm{H}_{2}$ Pc tetramer polymorph $\mathrm{a}$} \\
\hline $\mathrm{a}^{1}$ & 3.388 & & & & 3.4 \\
\hline$b^{2}$ & 3.715 & & & & 3.81 \\
\hline \multicolumn{6}{|c|}{$\mathrm{H}_{2} \mathrm{Pc}$ tetramer polymorph $\beta$} \\
\hline$a^{1}$ & 3.399 & & & & 3.4 \\
\hline$b^{2}$ & 4.833 & & & & 4.72 \\
\hline \multicolumn{6}{|c|}{$\begin{array}{l}1 \text { interplanar distance } \\
2 \text { the average distance of corresponding atoms } \\
{ }^{3} \text { stabilization energy of neutral dimers in } \mathrm{kcal} / \mathrm{mol}\end{array}$} \\
\hline
\end{tabular}


Calculated stabilization energies listed in Table 1 are typical for $\pi-\pi$ stacking interactions and indicate that the polymorph $\alpha$ is more stable than the $\beta$-modification; the calculated difference of stabilization energies is $1.5 \mathrm{kcal} / \mathrm{mol}$ for the functional MPW1B95. Table 1 shows that the withdrawal of electron from a polymorph leads to geometry with more closely lying interplanar arrangements of monomeric subunits characterized by the distances $\mathrm{a}=3.44 \AA$ and $\mathrm{b}=3.67 \AA$. Optimized geometry of anionic form is characterized by similar interplane distance $3.45 \AA$ and larger parameter $b=3.80 \AA$. Cationic form of $\beta$ polymorph is characterized by the distances $a=3.29 \AA$ and $b=5.26 \AA$, anionic form of this polymorph by distances $\mathrm{a}=3.33 \AA$ and $\mathrm{b}=3.68 \AA$. All following single point calculations were done at optimized geometries.

On the basis of the dimer calculations, the geometry optimization of $\mathrm{H}_{2} \mathrm{Pc}$ tetramer was done by MPW1B95/6-31G* calculations on both polymorphs. The middle part of the optimized tetramer structure interprets well the $\mathrm{H}_{2} \mathrm{Pc}$ crystal structure (the calculated interplane distance is $3.39 \AA$ [15]).

The optical spectroscopy was used for the characterization of the phthalocyanine layer. Figure 3 shows the experimental spectrum in the region of the phtalocyanine $Q$ band. The comparison of characteristic features of this spectrum with the previously measured spectra [36] of different polymorphs of $\mathrm{H}_{2}$ Pc layers indicates the presence of the $\alpha$ polymorph.

TD DFT calculated transitions on this polymorph reasonably well reproduce the strong features of characteristic $Q$ band and the effect of aggregation. The experimental transition energies measured at 1.77 and $1.93 \mathrm{eV}$ are slightly overestimated by TD DFT calculations (obtained at 2.15 and $2.21 \mathrm{eV}$ ) with oscillator strengths 0.52 and 0.58 , respectively. Transitions with low oscillator strength calculated at 1.65 and $1.71 \mathrm{eV}$ describe the appearance of the week features in the long wave region. The TD DFT calculation on the $\beta$ polymorph describes correctly the shift of the intense transitions to the longer wavelengths.

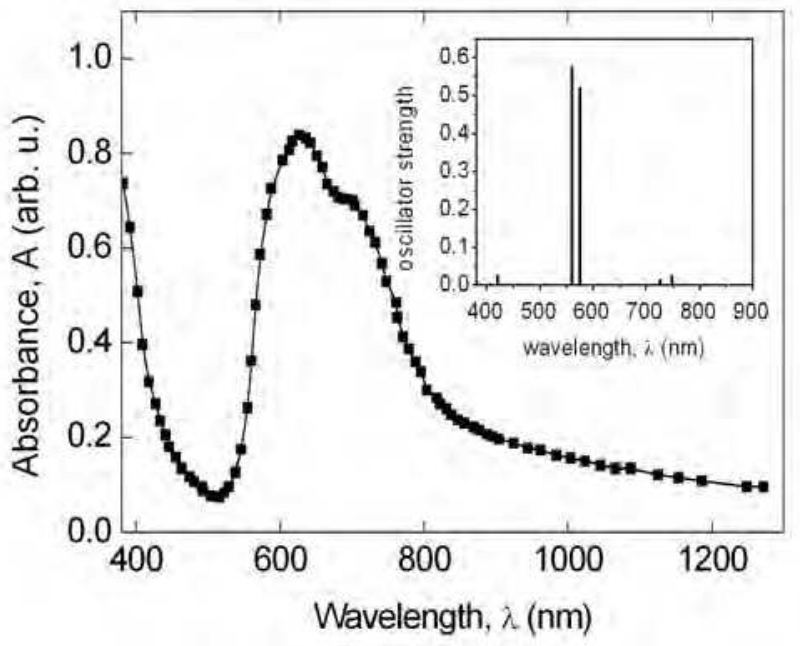

Fig. 3. The experimental spectrum of $\mathrm{H}_{2} \mathrm{Pc}$ layer in the region of the $\mathrm{Q}$ band. Inset shows calculated transitions for $\mathrm{H}_{2} \mathrm{Pc}$ dimer. 
At room temperature, the charge carrier transport can be described by a hopping within the Marcus theory. Subsequently, the rate expression of a self-exchange process is provided by the expression [19]

$$
k_{e t}=\frac{2 \pi}{\hbar} \frac{1}{\sqrt{4 \pi \lambda^{+} k T}}\left(t^{+}\right)^{2} \exp \left(-\frac{\lambda^{+}}{4 k T}\right),
$$

where $\hbar$ is the reduced Planck constant, $k$ is the Boltzmann constant, $T$ is the temperature an $\lambda^{+}$is the reorganisation energy and $t^{+}$is the electronic coupling matrix element (the measure of charge transport probability - electron transfer integral) for the charge transfer. In order to estimate the electronic coupling between individual monomeric units, electron transfer integrals were calculated for $\alpha$ and $\beta$ crystallographic modifications of the phthalocyanine dimer in HF approximation.

For the configuration with doubly occupied HOMO on the first monomer and singly occupied HOMO of the second one, calculation gives electron transfer integral (for otimized geometry MPW1B95/6-31G*) values for non-relaxed cation radical $11.7 \mathrm{meV}$ and $5.7 \mathrm{meV}$ (hole transfer) for the $\alpha$ and $\beta$ modification, respectively. It is supposed that in the course of electron or hole hopping, the atoms can relax in order to reach the minimum of energy at the potential surface. Transfer integral for optimized cation radical a crystal form with relaxed atoms (UMPW1B95/6-31G*) is $18.7 \mathrm{meV}$. The calculations indicate that electron mobility is smaller than hole mobility because optimized geometry of anionic form is characterized by larger interplane parameter $b$ (see Tab. 1) - for anionic form $b=3.804 \AA$, for cationic form $\mathrm{b}=3.665 \AA$ Á.

The transfer integral $t^{+}$was calculated according to

$$
t^{+}=\frac{H_{R P}-S_{R P}\left(H_{R R}+H_{P P}\right) / 2}{1-S_{R P}^{2}},
$$

$H_{R P}$ is the interaction energy between reactant and product states, $S_{R P}$ is the overlap between the reactant and product states and $\mathrm{H}_{R R}$ is electronic energy of the reaktant state and $\mathrm{H}_{\mathrm{PP}}$ is electronic energy of the product state. All these terms were obtained via the direct coupling of localised monomer orbitals. On the molecular level, three factors, the electronic coupling (transfer integral $t^{+}$) between the individual parts of the molecule, the reorganisation energy $\lambda^{+}$during charge transport and the effective length of hole transfer $L$, are usually considered to be important for charge transport in organic materials. The reorganization energy $\lambda^{+}$ consists of the sum of $\lambda_{1}{ }^{+}$and $\lambda_{2}{ }^{+}, \lambda^{+}=\lambda_{1}{ }^{+}+\lambda_{2}{ }^{+}$, where the deformation energy of the system was calculated as the difference between the vertical and cationic state: $\lambda_{1}{ }^{+}=E_{+}\left(Q_{N}\right)-E_{+}\left(Q_{+}\right)$ and $\lambda_{2}{ }^{+}=E_{+}\left(Q_{+}\right)-E_{+}\left(Q_{N}\right)$. Here, $E_{+}\left(Q_{N}\right)$ is the total electronic energy of the cationic state in the neutral geometry, $E_{+}\left(Q_{+}\right)$is the total energy of the cationic state in the cationic state geometry, $E_{N}\left(Q_{+}\right)$is the total energy of the neutral state in the cationic state geometry and $E_{N}\left(Q_{N}\right)$ is the total energy of the neutral state in the neutral geometry. $\lambda_{1}+$ is frequently called as deformation energy of the system.

The diffusion coefficient $D$ of charge carriers can be expressed using the EinsteinSmoluchowski equation 


$$
D=\frac{L^{2} k_{e t}}{2}
$$

This makes it possible to evaluate the drift mobility of the charge carriers using the Einstein relation $\mu=e D / k T$. It should also be noted that the calculated charge mobility mentioned here represents the zero electric field approximation value.

To explain the differences between the charge carrier mobility in sulphonated and nonsulphonated Ni phthalocyanines (NiPc), quantum chemical calculations were performed on the DFT (density functional theory) level for $\mathrm{H}_{2} \mathrm{Pc}, \mathrm{NiPc}_{\mathrm{P}}$ and $\mathrm{NiPc}\left(\mathrm{SO}_{3} \mathrm{Na}\right)_{x}(x=1,2)$ dimers and their cationic and anionic forms. Quantum chemical modeling was found to be very useful - we were able to see states of various molecular systems from new and comprehensive perspectives.

The optimized structure of the $\left[\mathrm{Ni}\left(\mathrm{Pc}\left(\mathrm{SO}_{3} \mathrm{Na}\right)_{2}\right)\right]_{2}$ is depicted in Fig.4. The calculated geometry of the NiPc dimer and tetramer reasonably well represents the local part of the NiPc crystal structure [34]. The best performance for the NiPc dimer was found by the MPW1B95/6-31+G* method. The calculated approximate interplane distance $(3.383 \AA)$ is close to the experimental value of $3.4 \AA[15,19]$.

The calculated stabilization energies are typical for $\Pi-\Pi$ stacking interactions. The calculated stabilization energies with the BSSE correction are 4.1, 5.4, 7.4 and $11.3 \mathrm{kcal} / \mathrm{mol}$ for the $\left[\mathrm{H}_{2} \mathrm{Pc}\right]_{2},[\mathrm{NiPc}]_{2},\left[\mathrm{NiPc}\left(\mathrm{SO}_{3} \mathrm{Na}\right)\right]_{2}$ and $\left[\mathrm{NiPc}\left(\mathrm{SO}_{3} \mathrm{Na}\right)_{2}\right]_{2}$ dimers, respectively. The MPWB1K/6$31 \mathrm{G}^{*}$ calculations yield similar results, whereas the calculated stabilization energies are slightly higher. The increasing stabilization energies in the series of dimers going from $\left[\mathrm{H}_{2} \mathrm{Pc}\right]_{2}$ to $\left[\mathrm{NiPc}\left(\mathrm{SO}_{3} \mathrm{Na}\right)_{2}\right]_{2}$ indicate the better stability and organization of the $\mathrm{NiPc}\left(\mathrm{SO}_{3} \mathrm{Na}\right)_{2}$ layers in comparison with the others.
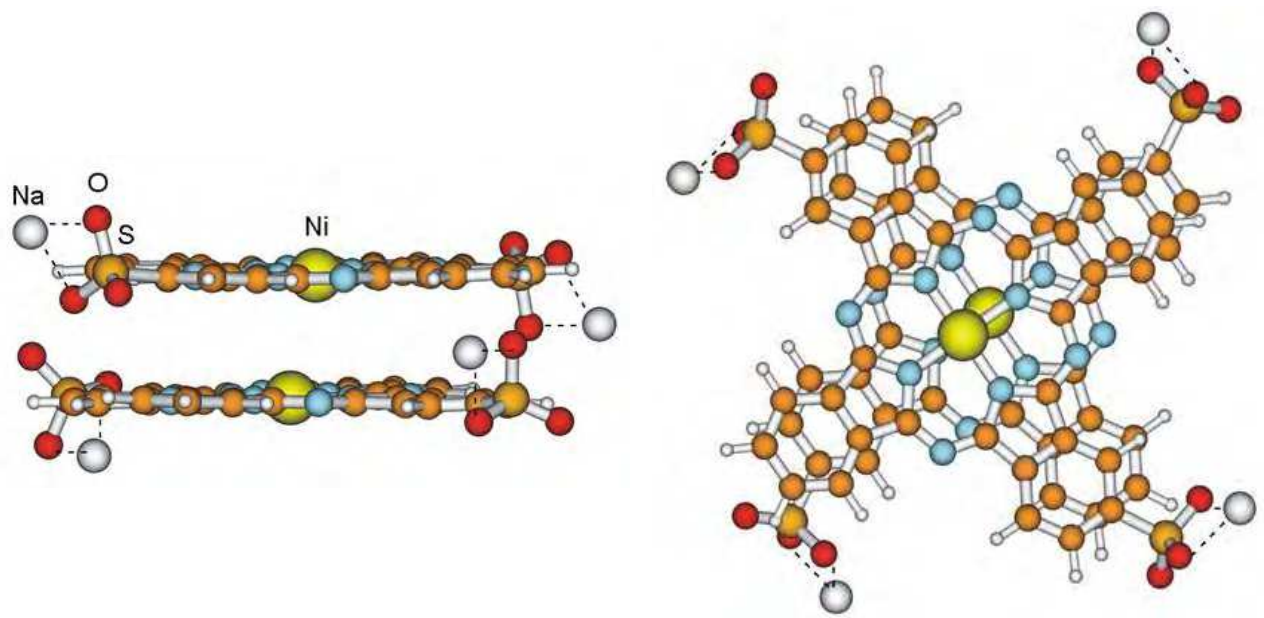

Fig. 4. The DFT-calculated optimized structure of the dimer $\left[\mathrm{NiPc}\left(\mathrm{SO}_{3} \mathrm{Na}\right)_{2}\right]_{2}$. The dashed line indicates the shortest distance between the $\mathrm{O}$ and $\mathrm{Na}$ atoms. 

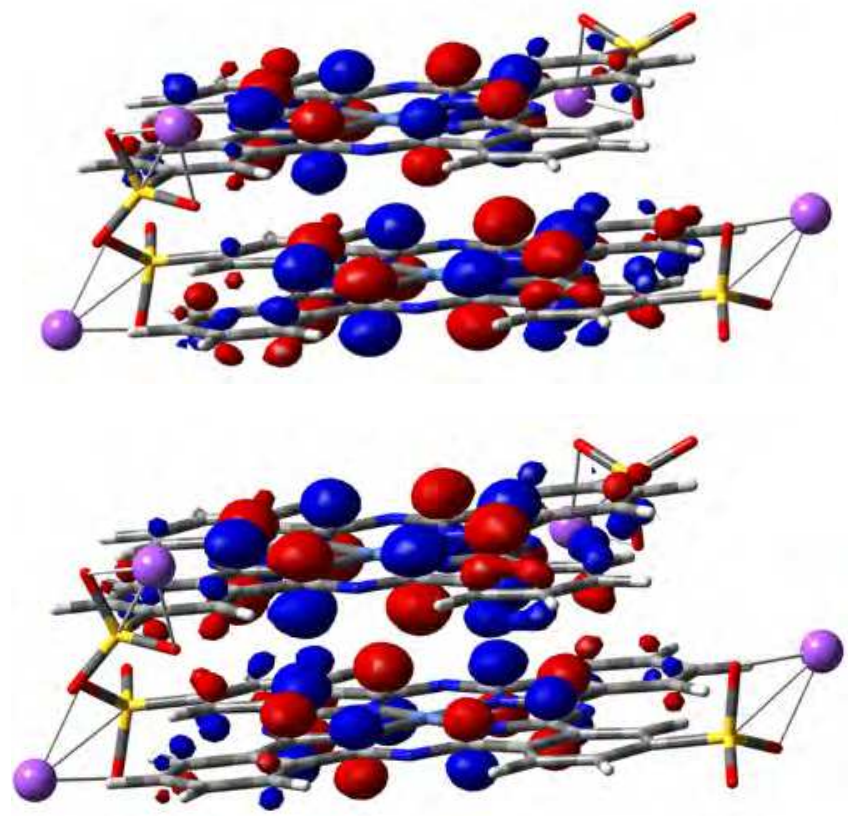

Fig. 5. The schematic representation of the HOMO (top) and HOMO-1 (bottom) of the dimer $\left[\mathrm{NiPc}\left(\mathrm{SO}_{3} \mathrm{Na}\right)_{2}\right]_{2}$.

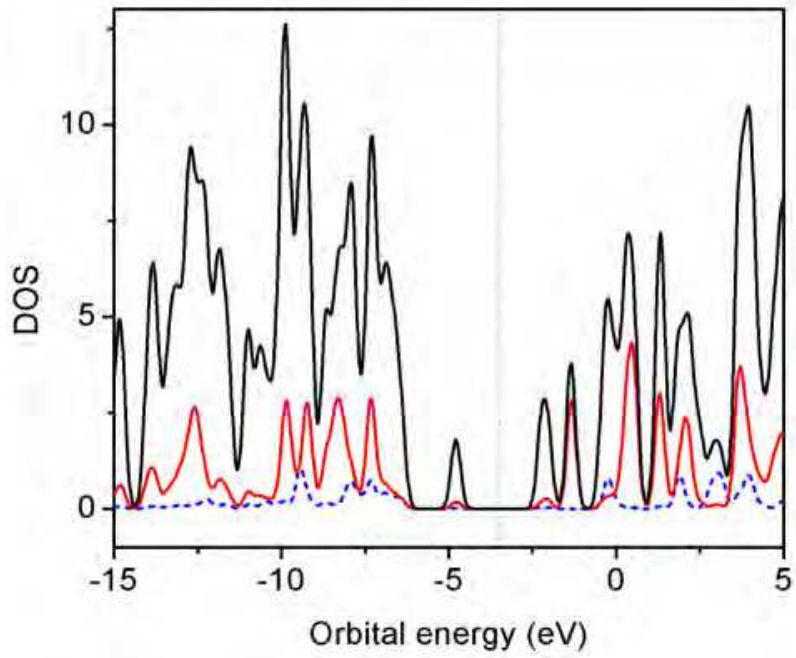

Fig. 6. The density of the states (DOS) for $\left[\mathrm{NiPc}\left(\mathrm{SO}_{3} \mathrm{Na}\right)_{2}\right]_{2}$. The black line indicates the total density of the states of the whole system, the blue dashed line the contributing Ni orbitals and the red one the contribution from the $\mathrm{SO}_{3} \mathrm{Na}$ group. The vertical dashed line indicates an approximate midpoint of the HOMO-LUMO levels. 


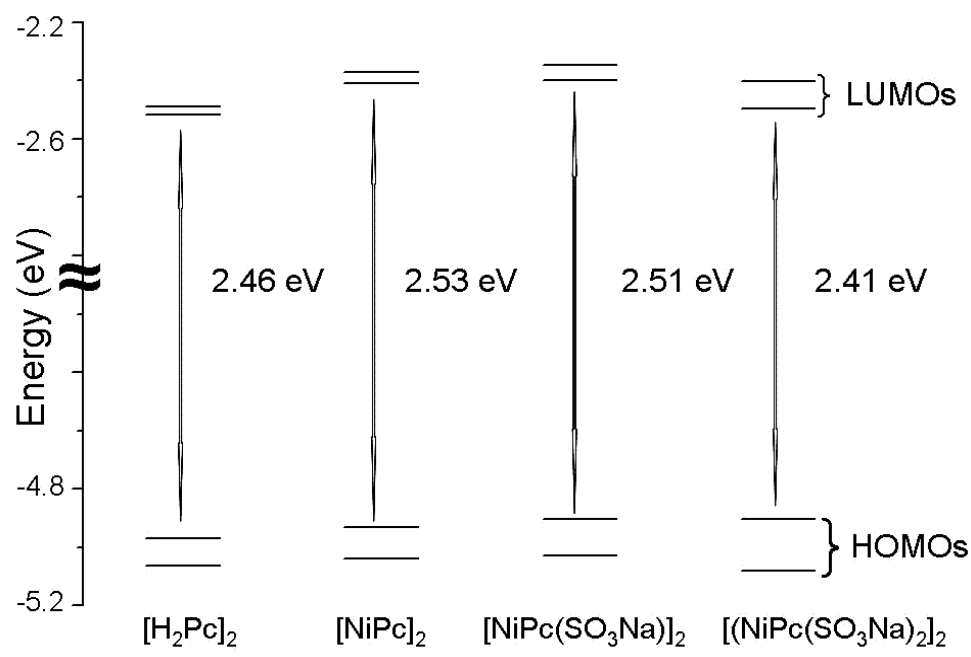

Fig. 7. The energies of the frontier orbitals of the studied phthalocyanine dimers.

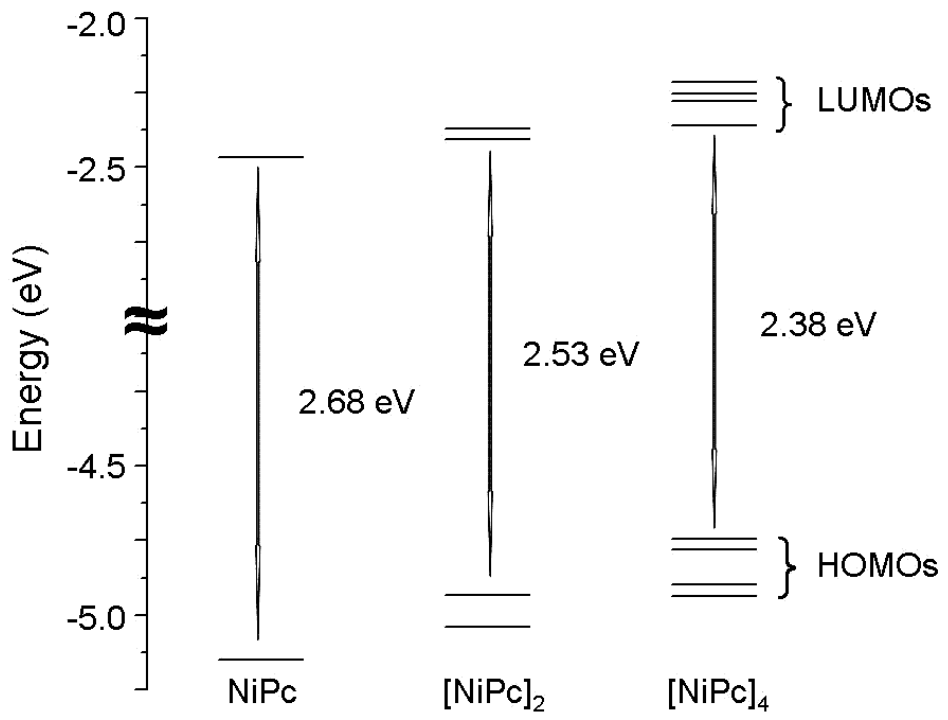

Fig. 8. The energies of the frontier orbitals of the NiPc monomer, dimer and tetramer. 


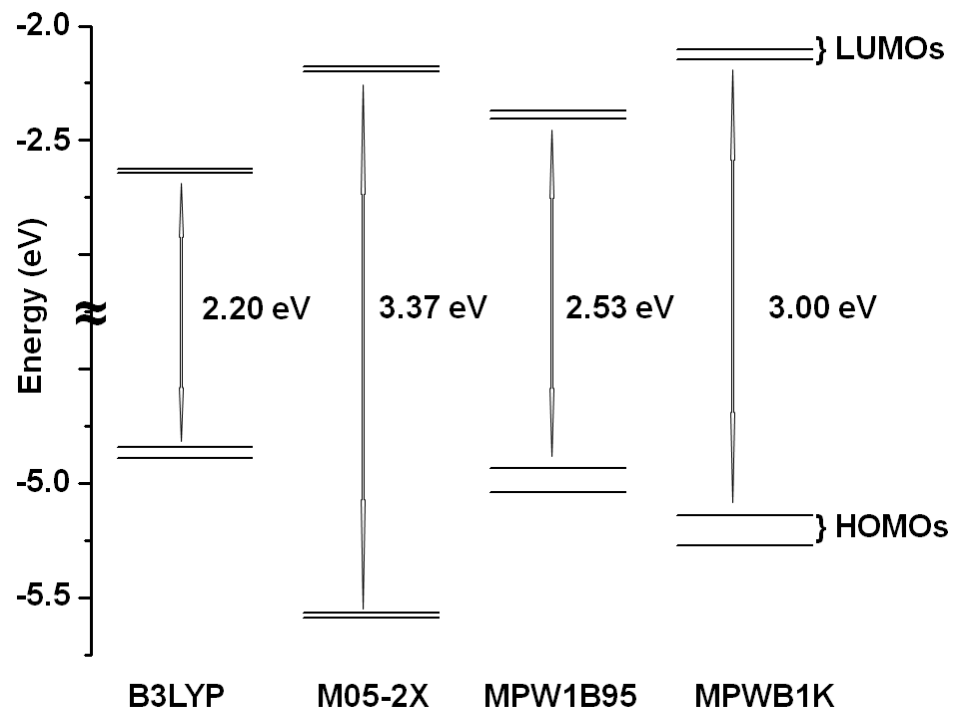

Fig. 9. The energies of the frontier orbitals of the NiPc dimer, calculated with different density functional for geometry optimized with corresponding functional.

Figure 5 depicts two highest occupied molecular orbitals (HOMO, HOMO-1) of $\left[\mathrm{NiPc}\left(\mathrm{SO}_{3} \mathrm{Na}\right)_{2}\right]_{2}$, the character of which can influence the hole conductivity. The plot of the density of the states in Fig. 6 shows the distribution of one-electron molecular orbitals and indicates that the $\mathrm{Ni}$ and $\mathrm{SO}_{3} \mathrm{Na}$ orbitals do not substantially contribute to the frontier molecular orbitals of the dimer $\left[\mathrm{NiPc}\left(\mathrm{SO}_{3} \mathrm{Na}\right)_{2}\right]_{2}$. These orbitals are formed by Pc $\pi$ orbitals. Owing to the mutual interaction of the $\pi$ monomer orbitals, the frontier orbitals of the supersystem form groups of two closely lying $\pi$ molecular orbitals. The contribution of the $3 \mathrm{~d}$ metal orbitals is negligible as in the case of the monomeric NiPc. The second pair of lower-lying occupied orbitals lies about $1.57 \mathrm{eV}$ lower. Thus, it can be supposed that these orbitals do not strongly influence the charge carrier transport. The calculated HOMOHOMO-1 separations are visualized in Figs. 7 and 8 while HOMO-LUMO gaps are listed in Tables 4 and 5. Figure 7 depicts the splitting of the frontier orbitals and their mutual position in the series of the systems studied; Fig. 8 compares orbital splitting in the series of the NiPc monomer, dimer and tetramer. The splitting of the frontier orbitals reflects the mutual interaction and thus the probability of charge transfer between individual monomeric subsystems. It should be mentioned that calculated HOMO-LUMO gap (Fig. 8) is diminishing in the series $\mathrm{NiPc},[\mathrm{NiPc}]_{2}$ and $[\mathrm{NiPc}]_{4}$ and approaching to the experimental value of $1.8 \mathrm{eV}$ [13]. Fig. 9 shows how the variation of functional influences the energies of frontier orbitals.

The rate constant $k_{E T}$ of the electron transfer between molecular orbitals was expressed - see (1). The electronic coupling between the individual monomeric units $V_{R P}$, the electrontransfer integral, can be calculated by several procedures [8-13]. Koopman's approximation, where the electronic coupling is estimated as half of the corresponding orbital energies, was used for the matrix-element estimation [14-18]. This method has already been used in the case of interacting metal-containing dimmers [22]. 
The values of the electron-transfer integrals for the closed-shell systems were estimated from the separation of HOMO and HOMO-1 for the optimized structures. The values of the electron-transfer integrals based on the MPW1B95/6-31G* functional model are $47.5 \mathrm{meV}$, $54.3 \mathrm{meV}, 63.1 \mathrm{meV}$ and $88.6 \mathrm{meV}$ for $\left[\mathrm{H}_{2} \mathrm{Pc}\right]_{2},[\mathrm{NiPc}]_{2},\left[\mathrm{NiPc}\left(\mathrm{SO}_{3} \mathrm{Na}\right)\right]_{2}$ and $\left[\mathrm{NiPc}\left(\mathrm{SO}_{3} \mathrm{Na}\right)_{2}\right]_{2}$, respectively (see Table 2).

\begin{tabular}{|c|c|c|c|c|}
\hline \multirow[b]{2}{*}{ Dimer } & \multicolumn{4}{|c|}{ MPW1B95/6-31G* } \\
\hline & $\Delta \mathrm{E}$ & $\Delta \mathrm{E}(\mathrm{BSSE})$ & ET coupling & Gap \\
\hline & \multicolumn{2}{|c|}{$\mathrm{kcal} \mathrm{mol}^{-1}$} & $\mathrm{meV}$ & $\mathrm{eV}$ \\
\hline$\left[\mathrm{H}_{2} \mathrm{Pc}\right]_{2}$ & 14.8 & 4.1 & 47.5 & 2.46 \\
\hline$[\mathrm{NiPc}]_{2}$ & 19.4 & 5.4 & 54.3 & 2.53 \\
\hline$\left[\mathrm{NiPc}\left(\mathrm{SO}_{3} \mathrm{Na}\right)\right]_{2}$ & 22.1 & 7.4 & 63.1 & 2.51 \\
\hline$\left[\mathrm{NiPc}\left(\mathrm{SO}_{3} \mathrm{Na}\right)_{2}\right]_{2}$ & 27.6 & 11.3 & 88.6 & 2.41 \\
\hline $\begin{array}{l}{\left[\left(\mathrm{NiPc}\left(\mathrm{SO}_{3} \mathrm{Na}\right)_{2}\right)\right.} \\
\left.\left(\mathrm{NiPc}\left(\mathrm{SO}_{3} \mathrm{Na}\right) \mathrm{SO}_{3}\right)\right]^{-}\end{array}$ & $31.2^{\mathrm{a}}$ & $13.2^{a}$ & & $2.34^{\mathrm{a}}$ \\
\hline$\left[\mathrm{NiPc}\left(\mathrm{SO}_{3} \mathrm{Na}\right)\left(\mathrm{SO}_{3}\right)\right]_{2^{2-}}$ & $6.3^{\mathrm{a}}$ & $-13.1^{a}$ & & $2.41^{\mathrm{a}}$ \\
\hline$\left[\mathrm{NiPc}\left(\mathrm{SO}_{3}\right)_{2}\right]_{2}{ }^{4-}$ & -79.4 & -100.5 & & 2.44 \\
\hline
\end{tabular}

a an average of the calculated values for the two different $\mathrm{Na}$ ions locations

Table 2 . The calculated stabilization energies $-\Delta \mathrm{E}$, (kcal/mol), electron-transfer integrals ET coupling (meV) and magnitude of the gap between the HOMO a LUMO orbitals of the various types of phthalocyanine dimers.

From these values, it follows that the electronic contribution to the rate constant of the electron transfer (proportional to the power of the electronic coupling $-V^{2} R P$ ) for $\left[\mathrm{NiPc}\left(\mathrm{SO}_{3} \mathrm{Na}\right)_{2}\right]_{2}$ should be 2.7 times larger than for $\left[\mathrm{NiPc}_{2}\right.$ and 3.5 times larger than for $\left[\mathrm{H}_{2} \mathrm{Pc}\right]_{2}$, whereas the electronic contribution for $\left[\mathrm{NiPc}\left(\mathrm{SO}_{3} \mathrm{Na}\right)\right]_{2}$ is only about 1.4 times larger than for $[\mathrm{NiPc}]_{2}$. The dependence of the electron-transfer integrals on the $\mathrm{Ni}-\mathrm{Ni}$ separation for $[\mathrm{NiPc}]_{2}$ and $\left[\mathrm{NiPc}\left(\mathrm{SO}_{3} \mathrm{Na}\right)_{2}\right]_{2}$ dimers is depicted in Fig. 10. The electron-transfer integral value varies strongly with the intermolecular separation, nevertheless the ratio between $V_{R P}$ calculated for $\mathrm{SO}_{3} \mathrm{Na}$ substituted and unsubstituted systems is close to this ratio obtained from equilibrium intermolecular separation.

Both water molecules surrounding or the application of an electric field can cause the dissociation of the ionic $\mathrm{Na}-\mathrm{SO}_{3}$ bond. In order to explain the effect of the $\mathrm{Na}^{+}$dissociation, calculations were performed on the model dimeric systems, where $\mathrm{Na}^{+}$ions were stepwise removed from the $\mathrm{NiPc}\left(\mathrm{SO}_{3} \mathrm{Na}\right)_{2}$ dimer . The stabilization energy of the system with one $\mathrm{Na}^{+}$ removed $\left(13.2 \mathrm{kcal} \mathrm{mol}^{-1}\right)$ is even larger than that of $\left[\mathrm{NiPc}\left(\mathrm{SO}_{3} \mathrm{Na}\right)_{2}\right]_{2}$. From Table 2, it can be seen that $\left[\mathrm{Ni}_{2} \mathrm{Pc}_{2}\left(\mathrm{SO}_{3} \mathrm{Na}\right)_{3}\left(\mathrm{SO}_{3}\right)\right]^{-}$is the most stable and thus the best organized of all the structures investigated. The density of the states plot depicted in Fig. 11 shows how the withdrawal of one $\mathrm{Na}^{+}$influences the electronic structure. Projected Densities of States reported in this chapter were broadened using discrete molecular orbital levels - the broadening parameter used in our PDOS calculations (the full width at half maximum) was $0.3 \mathrm{eV}$. 


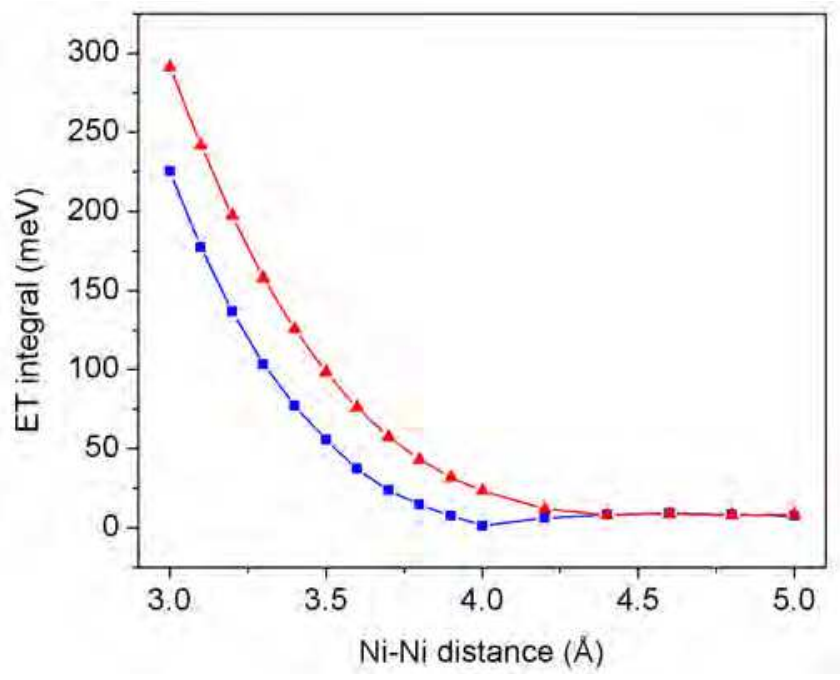

Fig. 10. The dependence of electron-transfer integrals on the Ni-Ni separation. $\left[\mathrm{NiPc}_{2}-\right.$ blue squares, $\left[\mathrm{NiPc}\left(\mathrm{SO}_{3} \mathrm{Na}\right)_{2}\right]_{2}$ - red triangles.

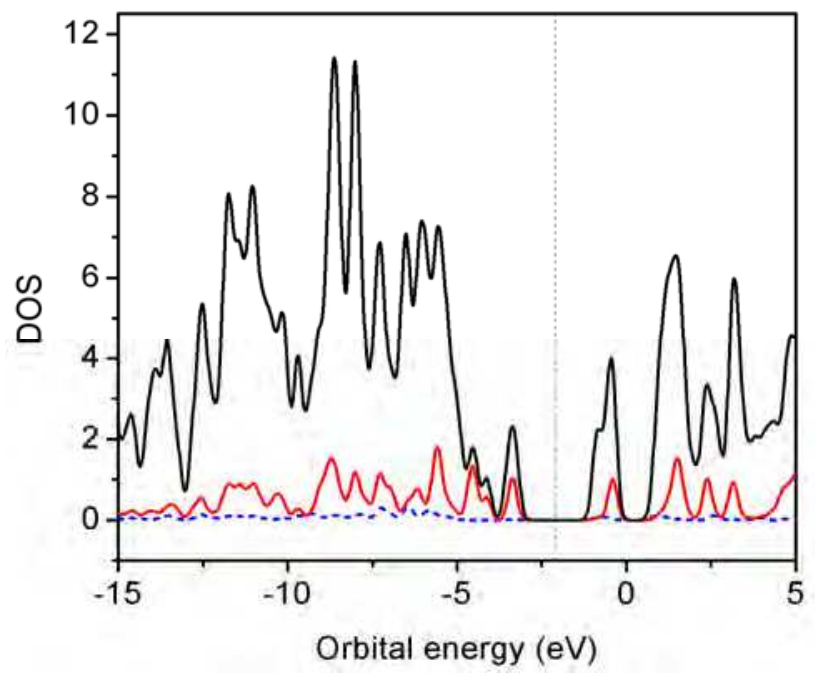

Fig. 11. The density of the states (DOS) for the system $\left[\mathrm{Ni}_{2} \mathrm{Pc}_{2}\left(\mathrm{SO}_{3} \mathrm{Na}\right)_{3}\left(\mathrm{SO}_{3}\right)\right]$-. the black line indicates the total density of the states of the whole system, the blue dashed line the contributing $\mathrm{Ni}$ orbitals and the red one the total contribution from the $\mathrm{SO}_{3} \mathrm{Na}$ and $\mathrm{SO}_{3}$ groups; the vertical dashed line indicates an approximate midpoint of the HOMO-LUMO levels.

In comparison with the unperturbed system, the set of HOMOs is no longer separated from the lower-lying occupied orbitals and contains contributions from the $\mathrm{SO}_{3}{ }^{-}$group. It can be supposed that after $\mathrm{Na}^{+}$ion dissociation the whole layer contains mobile $\mathrm{Na}^{+}$and fixed $\left[\mathrm{NiPc}\left(\mathrm{SO}_{3} \mathrm{Na}\right)\left(\mathrm{SO}_{3}\right)\right]$ - ions surrounded by water molecules. In this case, the highest molecular 
orbitals, which contain contributions from the $\mathrm{SO}_{3}{ }^{-}$group and are close to the lower-lying occupied orbitals, allow the whole system to contain electronic states that are more extended and therefore more conductive in character.

Due to the withdrawal of the remaining $\mathrm{Na}^{+}$ions, the stabilization energies decrease. The least stable dimer in the series $\left[\mathrm{NiPc}\left(\mathrm{SO}_{3} \mathrm{Na}\right)_{2}\right]_{2},\left[\mathrm{NiPc}\left(\mathrm{SO}_{3} \mathrm{Na}\right)\left(\mathrm{SO}_{3}\right)\right]_{2} 2^{2-}$ and $\left[\mathrm{NiPc}\left(\mathrm{SO}_{3}\right)_{2}\right]_{2}{ }^{4-}$ is the last, completely dissociated dimer, i.e. $\left[\mathrm{NiPc}\left(\mathrm{SO}_{3}\right)_{2}\right]_{2^{4-}}$. This fact can induce reduced layer organization and thus lower the conductivity of the systems with more than one $\mathrm{Na}^{+}$ion removed.

How can the selected chemical modifications of Ni phthalocyanine affect on the molecular level the charge carrier mobility?

At zero-gate bias, the HOMO band is filled. As the gate voltage is swept more negative, the positions of the LUMO and HOMO bands rise in energy, allowing mobile holes to sustain a source-drain current via the $\mathrm{HOMO}$ band. Materials based on $\mathrm{NiPc}$ and $\left[\mathrm{NiPc}\left(\mathrm{SO}_{3} \mathrm{Na}\right)_{x}\right]$ are hole semiconductors, which means that the source of the charge carriers in the structure electrode-semiconductor - electrode is not the injecting metal electrode but the semiconductor. In the case of $\left[\mathrm{NiPc}\left(\mathrm{SO}_{3} \mathrm{Na}\right)\left(\mathrm{SO}_{3}\right)\right]$, the contribution from the $\mathrm{SO}_{3}$ anions to the whole HOMO orbital system enables the mobile holes to be more delocalized; thus the change charge transport (hopping) mechanism becomes more ballistic (less scattered and more effective).

The stability of dimers (the calculated stabilization energy), which induces better layer organization and consequently better charge mobility ${ }^{37}$ grows in the series $\left[\mathrm{H}_{2} \mathrm{Pc}\right]_{2},\left[\mathrm{NiPc}_{2}\right.$, $\left[\mathrm{NiPc}\left(\mathrm{SO}_{3} \mathrm{Na}\right)\right]_{2},\left[\mathrm{NiPc}\left(\mathrm{SO}_{3} \mathrm{Na}\right)_{2}\right]_{2}$ and $\left[\left(\mathrm{NiPc}\left(\mathrm{SO}_{3} \mathrm{Na}\right)_{2}\right)\left(\mathrm{NiPc}_{2}\left(\mathrm{SO}_{3} \mathrm{Na}\right) \mathrm{SO}_{3}\right)\right]^{-}$. The withdrawal of more than one $\mathrm{Na}$ cation leads to destabilization and consequently to a decrease in layer organization. The layer of $\left[\mathrm{Ni}_{2} \mathrm{Pc}_{2}\left(\mathrm{SO}_{3} \mathrm{Na}\right)_{3}\left(\mathrm{SO}_{3}\right)\right]^{-}$should be the most regular (is supposed to be the most conductive) of all the structures examined.

In the case of $\mathrm{NiPc}\left(\mathrm{SO}_{3} \mathrm{Na}\right)_{3.3}$ the charge carrier mobility $\left(0.02 \mathrm{~cm}^{2} \mathrm{~V}^{-1} \mathrm{~s}^{-1}\right)$ is lower than for $\mathrm{NiPc}\left(\mathrm{SO}_{3} \mathrm{Na}\right)_{1.5}\left(1.08 \mathrm{~cm}^{2} \mathrm{~V}^{-1} \mathrm{~s}^{-1}\right)$ - see Tab. 3 .

\begin{tabular}{ccc}
\hline Phthalocyanine & Film preparation & Mobility $\left(\mathrm{cm}^{2} \mathrm{~V}^{-1} \mathrm{~s}^{-1}\right)$ \\
\hline $\mathrm{NiPc}$ & evaporation & $10^{-5}$ \\
$\mathrm{NiPc}\left(\mathrm{SO}_{3} \mathrm{Na}\right)_{3.3}$ & spin-coating & 0.02 \\
$\mathrm{iPc}\left(\mathrm{SO}_{3} \mathrm{Na}\right)_{1.5}$ & spin-coating & 1.08 \\
\hline
\end{tabular}

Table 3. The mobilities for the various types of nickel phthalocyanines.

From calculating spatial models it was figured out that due to the sterical communication hindrance caused by third and fourth $\mathrm{SO}_{3} \mathrm{Na}$ groups the $\mathrm{NiPc}\left(\mathrm{SO}_{3} \mathrm{Na}\right)_{3.3}$ dimers are less stable. This fact results in reduced organized layer structure with reduced charge mobility.

Using DFT calculations, several aspects that influence the charge-carrier mobility in the case of the materials were compared:

1. Charge transfer probability grows in the series $\left[\mathrm{H}_{2} \mathrm{Pc}\right]_{2},[\mathrm{NiPc}]_{2},\left[\mathrm{NiPc}\left(\mathrm{SO}_{3} \mathrm{Na}\right)\right]_{2}$ and $\left[\mathrm{NiPc}\left(\mathrm{SO}_{3} \mathrm{Na}\right)_{2}\right]_{2}$ because of the increasing electronic coupling. The presence of $\left(\mathrm{SO}_{3} \mathrm{Na}\right)$ groups increases the probability of electron transfer between the composing units.

2. At the same time, the stabilization energies grow in the series $\left[\mathrm{H}_{2} \mathrm{Pc}\right]_{2},\left[\mathrm{NiPc}_{2}\right.$ and $\left[\mathrm{NiPc}\left(\mathrm{SO}_{3} \mathrm{Na}\right)_{2}\right]_{2}$. Due to larger stabilization energies of the systems with $\left(\mathrm{SO}_{3} \mathrm{Na}\right)$ 
groups, it can be assumed that layers with $\left(\mathrm{SO}_{3} \mathrm{Na}\right)$ groups are organized more regularly - resulting in better $\pi-\pi$ interaction and consequently better charge carrier mobility than in the case of nonsubstituted ones. The withdrawal of one $\mathrm{Na}^{+}$ion leads to a further stabilization of the structure and thus a higher probability of charge-carrier transport. The dissociations of more than one $\mathrm{Na}^{+}$ion strongly destabilize the layer structure. The probability of charge transfer through sulphonated Ni-phthalocyanine dimers with totally removed $\mathrm{Na}^{+}$ions should, therefore, be lower than in the case of standard sulphonated Ni phthalocyanines dimers.

3. The system is strongly affected by an external electric field and water molecules in the vicinity, which can cause the dissociation of the ionic $\mathrm{Na}-\mathrm{SO}_{3}$ bond. After the $\mathrm{Na}-\mathrm{SO}_{3}$ bond's dissociation, the whole layer contains mobile $\mathrm{Na}^{+}$and fixed $\left[\mathrm{Ni}_{2} \mathrm{Pc}_{2}\left(\mathrm{SO}_{3} \mathrm{Na}\right)_{3}\left(\mathrm{SO}_{3}\right)\right]^{-}$ anions which allows the mobile holes to delocalize and increase the probability of hole transfer through the layer structure. We found that the highest molecular orbitals in $\left[\mathrm{Ni}_{2} \mathrm{Pc}_{2}\left(\mathrm{SO}_{3} \mathrm{Na}\right)_{3}\left(\mathrm{SO}_{3}\right)\right]$ - contain new electronic contributions to the density of the states from the $\mathrm{SO}_{3}$-group, which should lead to an increase in the hole mobility and thus conductivity.

Other aspects which can increase charge carrier mobility in of the OFET structures based on sulphonated phthalocyanine derivatives should be mentioned: 1 . Better resistivity to oxygen and thus the stability of the system in atmospheric air. 2. The interface $\mathrm{SiO}_{2} /\left[\mathrm{NiPc}\left(\mathrm{SO}_{3} \mathrm{Na}\right)_{2}\right]_{x}$ is between two hydrophilic groups and thus adheres materials enabling the formation of a molecular layer on the $\mathrm{SiO}_{2}$ surface with proper and regular molecular orientation which increases the conductivity .

The objective of this chapter was to present results of DFT studies of class of organic materials with relatively high carrier mobility - phthalocyanines. It was shown how DFT can be used to calculate/model some parameters that influence charge carrier mobility on essentially level [18]. The calculations indicate that electron mobility in $\mathrm{H}_{2} \mathrm{Pc}$ is smaller than hole mobility because optimized geometry of anionic form is characterized by larger interplane parameter.

In the case of $\left[\mathrm{NiPc}\left(\mathrm{SO}_{3} \mathrm{Na}\right)\left(\mathrm{SO}_{3}\right)\right]^{-}$, the contribution from the $\mathrm{SO}_{3}$ anions to the whole HOMO orbital system enables the mobile holes to be more delocalized; thus the change charge transport (hopping) mechanism becomes more ballistic (less scattered and more effective). The withdrawal of one $\mathrm{Na}^{+}$ion leads to a further stabilization of the structure and thus a higher probability of charge-carrier transport.

- Larger stabilization energies of the systems with $\left(\mathrm{SO}_{3} \mathrm{Na}\right)$ groups - layers with $\left(\mathrm{SO}_{3} \mathrm{Na}\right)$ groups are organized more regularly - resulting in better $\Pi-\Pi$ interaction and consequently better charge carrier mobility than in the case of nonsubstituted ones.

- The withdrawal of one $\mathrm{Na}+$ ion leads to a further stabilization of the structure and thus a higher probability of charge-carrier transport.

- The dissociations of more than one $\mathrm{Na}+$ ion strongly destabilize the layer structure. The probability of charge transfer through sulphonated Ni-phthalocyanine dimers with totally removed $\mathrm{Na}+$ ions is lower than in the case of standard sulphonated $\mathrm{Ni}$ phthalocyanines dimers.

\section{References}

[1] M. A. Reed, Proc. IEEE , $1999,87,652$.

[2] D. Braga, G. Horowitz, Adv. Mater., 2009, 21, 1.

[3] J. Health, M. Read, Molecular Electronics, Physics Today, 2003, 43 
[4] C.P. Collier et al., Science, 2000, 289, 1172

[5] A.J. Heinrich et al. Science, 2002, 298, 1381

[6] J. Park et al. Nature, 2002, 417, 722

[7] M. Taniguchi and T. Kawai, Physica E 2006, 33 1-12.

[8] S. Datta, W. Tian, S. Hong, R. Reifenberger, I. Henderson, and C. Kubiak, Phys.Rev.Lett. 1997, 79 2530-2533.

[9] F. Zahid, M. Paulsson and S. Datta, Chapter published in "Advanced Semiconductors and Organic nano-Techniques", edited by H. Morkoc, Academic Press 2003. See also arXiv: Cond-Mat/0208183.

[10] K. Müllen, G. Wegner (Eds.), Electronic Materials: The Oligomeric Approach (Wiley-VCH, Weinheim, 1998).

[11] J. Simon, P. Bassoul, Design of Molecular Materials. Supramolecular Engineering (Wiley, Chichester, 2000).

[12] R.G. Enders, D. L. Cox, and R.R.P. Singh, Colloquium: Rev. Modern Phys.2004, 76 195-217.

[13] L. Cai, H. Tabata, and T. Kawai, Self-assembled DNA networks and their electrical conductivity, Appl. Phys. Let. 2000, 77 3105-3106.

[14] I. Kratochvílová, S. Nešpůrek, J. Šebera, S. Záliš, M. Pavelka, G. Wang, J. Sworakowski, Eur. Phys. J. E, 2008, 25, 299.

[15] I. Kratochvílová, K. Král, M. Bunček, A. Vúšková, S. Nešpůrek, A. Kochalska, T. Todorciuc, M. Weiter, B. Schneider, Biophys. Chem., 2008, 138, 3.

[16] I. Kratochvílová, K. Král, M. Bunček, S. Nešpưrek, T. Todorciuc, M. Weiter, J. Navrátil, B. Schneider and J. Pavluch, Cent. Eur. J. Phys., 2008, 6, 422.

[17] S. Záliš, I. Kratochvílová, A. Zambova, J. Mbindyo, T. E. Mallouk, T. S. Mayer, Eur. Phys. J. E, 2005, 18, 201.

[18] M. F Craciun, S Rogge, M - J. L. Den Boer, S Margadonna, K Prassides, Y Iwasa, A. F Morpurgo, Advanced Materials 18, (2006) 320.

[19] I.I. Fishchuk, A. Kadashchuk, V.N. Poroshin, N. Volodymyr, H. Bassler, Philosophical Magezine, 90 (2010) 129.

[20] J. Šebera, S. Nešpưrek, I. Kratochvílová, S. Záliš, G. Chaidogiannos, N. Glezos, European Physical Journal B 72 (2009) 385.

[21] M. C. Reese, M. Roberts, M. Ling and Z. Bao, Mater. Today, 2004, 7, 20.

[22] C. D. Dimitrakopoulos, P. R. L. Malenfant, Adv. Mater., 2002, 14, 99.

[23] R. Zeis, T. Siegrist and C. Kloc, Appl. Phys. Lett., 2005, 86, 022103.

[24] S. Nešpůrek, G. Chaidogiannos, N. Glezos, G. Wang, S. Böhm, J. Rakušan, M. Karásková, Mol. Cryst. Liq. Cryst., 2007, 468, 355.

[25] F. Yang, M. Shtein and S. R. Forrest, Nat. Mater., 2005, 4, 37.

[26] Jakub Šebera, Stanislav Nešpůrek, Irena Kratochvílová, Stanislav Záliš, George Chaidogiannos, Nikos Glezos, European Physical Journal B - Condensed Matter and Complex Systems 72 (2009) 385-395.

[27] S. M. Bayliss, S. Heutz, G. Rumbles, T. S. Jones, Phys. Chem. Chem. Phys. 1, 3673 (1999)

[28] R.D. Gould, Coord.Chem. Rev. 156, 237 (1996)

[29] M. Ashida, N. Uyeda, E. Suito, Bull. Chem. Soc. Jpn. 39, 2616 (1966)

[30] A. Farazdel, M. Dupuis, E. Clementi, A. Aviram, J. Am. Chem. Soc. 112, 4206 (1990)

[31] V. Coropceanu, J. Cornil, D.A. da Silva Filho, Y. Olivier, R. Silbey, J. L. Brédas, Chem. Rev. 107, 926 (2007)

[32] Hynek Nemec, Irena Kratochvilova, Petr Kuzel, Jakub Sebera, Anna Kochalska, Juraj Nozar and Stanislav Nespurek, Phys. Chem. Chem. Phys., 2011, 13, 2850-2856 


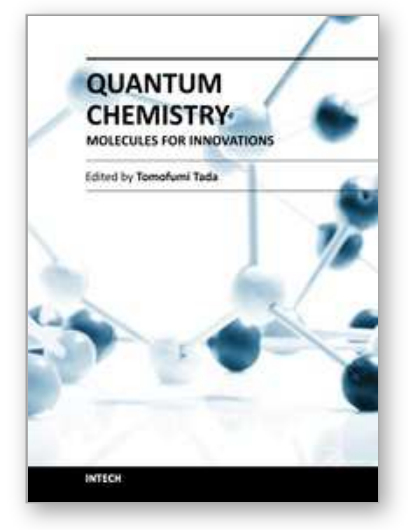

\author{
Quantum Chemistry - Molecules for Innovations \\ Edited by Dr. Tomofumi Tada
}

ISBN 978-953-51-0372-1

Hard cover, 200 pages

Publisher InTech

Published online 21, March, 2012

Published in print edition March, 2012

Molecules, small structures composed of atoms, are essential substances for lives. However, we didn't have the clear answer to the following questions until the 1920s: why molecules can exist in stable as rigid networks between atoms, and why molecules can change into different types of molecules. The most important event for solving the puzzles is the discovery of the quantum mechanics. Quantum mechanics is the theory for small particles such as electrons and nuclei, and was applied to hydrogen molecule by Heitler and London at 1927. The pioneering work led to the clear explanation of the chemical bonding between the hydrogen atoms. This is the beginning of the quantum chemistry. Since then, quantum chemistry has been an important theory for the understanding of molecular properties such as stability, reactivity, and applicability for devices. This book is devoted for the theoretical foundations and innovative applications in quantum chemistry.

\title{
How to reference
}

In order to correctly reference this scholarly work, feel free to copy and paste the following:

Irena Kratochvilova (2012). Charge Carrier Mobility in Phthalocyanines: Experiment and Quantum Chemical Calculations, Quantum Chemistry - Molecules for Innovations, Dr. Tomofumi Tada (Ed.), ISBN: 978-953-510372-1, InTech, Available from: http://www.intechopen.com/books/quantum-chemistry-molecules-forinnovations/charge-carrier-mobility-in-phthalocyanines-experiment-and-quantum-chemical-calculations

\section{INTECH}

open science | open minds

\author{
InTech Europe \\ University Campus STeP Ri \\ Slavka Krautzeka 83/A \\ 51000 Rijeka, Croatia \\ Phone: +385 (51) 770447 \\ Fax: +385 (51) 686166 \\ www.intechopen.com
}

\author{
InTech China \\ Unit 405, Office Block, Hotel Equatorial Shanghai \\ No.65, Yan An Road (West), Shanghai, 200040, China \\ 中国上海市延安西路65号上海国际贵都大饭店办公楼 405 单元 \\ Phone: +86-21-62489820 \\ Fax: +86-21-62489821
}


(C) 2012 The Author(s). Licensee IntechOpen. This is an open access article distributed under the terms of the Creative Commons Attribution 3.0 License, which permits unrestricted use, distribution, and reproduction in any medium, provided the original work is properly cited. 